\section{ECONOMICS}

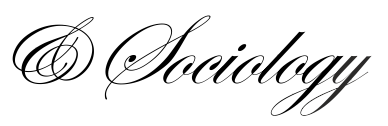

Banegas Rivero, R. A., Núñez Ramírez, M. A., \& Valdez del Río, S. (2020).

Business cycle, asymmetries and non-linearity: The Bolivian case. Economics and

Sociology, 13(2), 26-42. doi:10.14254/2071-789X.2020/13-2/2

\title{
BUSINESS CYCLE, ASYMMETRIES AND NON-LINEARITY: THE BOLIVIAN CASE
}

\author{
Roger Alejandro Banegas \\ Rivero \\ Department of Economics, \\ Universidad Autónoma Gabriel \\ René Moreno, Bolivia, \\ E-mail: rbanegas@,uagrm.edu.bo \\ ORCID 0000-0002-3841-786X \\ Marco Alberto Núñez \\ Ramírez \\ Department of Management, \\ Instituto Tecnológico de Sonora, \\ Mexico, \\ E-mail: \\ marco.nunez@itson.edu.mx \\ ORCID 0000-0001-5825-4482 \\ Corresponding Author
}

\author{
Sacnicté Valdez del Río \\ Department of Management, \\ InstitutoTecnológico de Sonora, \\ Mexico, \\ E-mail: \\ sacnicte.valder@itson.edu.mx \\ ORCID 0000-0002-1786-5567
}

Received: October, 2019

1st Revision: March, 2020

Accepted: May, 2020

DOI: $10.14254 / 2071$ -

789X.2020/13-2/2

JEL Classification: F44, F47
ABSTRACT. In this paper, we deal with the problem of measuring business cycles: short, medium or long-term, with both theoretical and empirical discussions on the regularity of fluctuations versus asymmetries in their measurement phases. To achieve this, the approach is based on the combination of deviations on the level of trends (alternative filters) with the algorithm of Harding and Pagan (2002). At the same time, effective rates of economic growth by Markov's chains was considered in order to identify non-linear regimes of expansion and economic contraction. Finally, quantifications on the natural rate of growth for Bolivia are offered under a sustained expansion regime from 1950 to 2015. The results suggest that due to asymmetries and the manner in which the business cycle is measured, we observe longer duration of a business cycle when it was measured from busts rather than from booms.
Keywords: Markovs' chains, business cycle, natural rate of growth, Bolivia. 


\section{Introduction}

Characterization of a business cycle focuses on the succession of its economic phases: expansion, peak, slowdown or a drop in the economic activity until the point of troughs is reached (Mitchell, 1927). Likewise, it has been pointed out that peaks and valleys are often used as turning points in the growth of an economy (Alfonso et al., 2013). Usually, duration of a business cycle can be identified, either from top to top (peak to local maximum) or from troughs to troughs (minimum to local minimum).

Throughout the history, there has been some discussion about the duration, with short cycles lasting around 40 months, Kitchen cycles; medium cycles with the duration between 9 1/4 (Juglar), 10 9/12 (Jevons) and 18 1/13 years (Kuznets); and also long-term cycles (with the duration of 54 years, Kondratiev cycles) (Pruden, 1978).

In contrast, at the beginning of the XXth century, the irregularity was pointed out in the duration of such cycles (Mitchel, 1913), with movements of the actual production being around a trend and not explained by the determinants of the production function (Lucas, 1975), and having asymmetries properties in the probability of transition and duration between expansion, recession and non-linearity (Neftci, 1984; Hamilton, 1989; Engel and Hamilton, 1990; Terasvirta and Anderson, 1992).

In the case of Bolivian economy, conclusions are reached with somewhat contradictory evidence: on the one hand, support for short-term cycles, from 2 to 7 years (Valdivia and Yujra, 2009), is contrasted with long-term cycle results of about 30 years (Mercado, Leitón, and Chacón, 2005; Humérez and Dorado, 2006).

The main purpose of this article is to evaluate the problems encountered in the duration of the business cycle in Bolivia,1950 to 2015. Our evaluation is based on three alternative measurements of economic growth - per capita income, income per worker, and real product. For this reason, the Harding and Pagan (2002) method was utilized, based on the reports by Bry and Boschan (1971)[BB], while identifying the turning points between the maximum and the relative minimum output gap. Additionally, we intend to demonstrate non-linearity between the average duration in expansion and contraction regimes, from the effective rate of growth. The final part of the paper is focused on estimating the natural rate under the sustained growth regime approach.

Accordingly, the paper is structured in four sections: the first one addresses the review of literature related to business cycles, asymmetries and empirical strategies for Bolivia; the second section contemplates between the data and the used econometric specifications; the third section deals with the results of our estimations; the fourth one presents a discussion on the findings and the research agenda. At the end, conclusions and discussion are presented.

\section{Literature review}

\section{The business cycle, asymmetries, and empirical strategy for Bolivia}

Since the initial contribution of Jevons $(1874 ; 1884)$, the study was conducted due to economic fluctuations based on the relationship between solar cycles, climatic cycles, cycles of the agricultural sector and its link with the cycle of commercial credit, accompanied by social, political and economic factors with an average duration of 10.8 years -based on the context of the nineteenth century - as well as the incidence in different regions (tropical or sub-tropical) (Morgan, 1990). However, Jevons's theory was rejected and ridiculed by modern economists, interpreted as spurious (false) relationships or meaningless correlations (Yule, 1926). Similarly, 
other economists associated the business cycle with the climate and temperature cycle (Moore, 1914).

Moreover, later contributions of Juglar (1862) pointed to the variations in the credit offer as the common cause during the business cycle, as well as their respective categorization which include: prosperity (5-7 years), panic and crises (months or years), and the return of the crises every 5 or 10 years.

Contrary to previous versions, Mitchel(1913) concluded that the cycles were uniform and therefore, were not uniform with different designs and phases that differed over time, indicating that it could be foreseen and controlled in the future cycles; however, till date, this expectation is yet to be resolved and poses one of the main challenges for economic science. The critique of Mitchel's analysis focused only on the analysis without the theory of economic phenomena: we would have to observe the dynamics of the temporal series rather than theorize (the data speak for themselves) (Koopmans, 1947).

Subsequently, the theoretical contributions of Burns and Mitchell (1946) were linked to the use of individuals from economy sectors which provide measures of the business cycle and identify their phases of expansion, boom, recession and depression in terms of spin points (increase to decrease, and reverse).

The contribution of Lucas (1975) gave a clearer picture on the regularities of the business cycle, as the movements of the gross national product around a trend are not explained by the movements of the production factors. In addition, the main pro-cyclical movements (in the same direction) are evident in prices, investment, and the nominal rate of interest through expectation mechanisms.

The trend measurement in applied macroeconomics is oriented to the path of expansion in potential product or steady state of growth, which can be related to the rate of technological change in softened mechanism. The work of Kydland \& Prescott (1990) provided an orientation showing the co-movements of the macroeconomic series with the gross national product (GNP) and the synchronizations. Alternative measurements are needed to maintain consistency in estimations and avoid analysis of spurious fluctuations. On the other hand, the basic definition of asymmetry states that the average duration of the expansion phase is different from the average duration of the recession phase, so the cycle is asymmetric. Thus, for Nefci's (1984) contribution with Markov's processes of second-order, the symmetry of the business cycle is incorporated as equality between the probability of positive sign change to negative sign, with the probability of transition in opposite sign; otherwise, if the properties of the business cycle substantially differ in the duration of its phases, it leads to asymmetric cycles.

An alternative definition indicates the presence of asymmetry when the negative phases present greater persistence than the positive phases (Sichel, 1993). In fact, two types of asymmetries are defined between their depth phases and recovery level (steep series). 

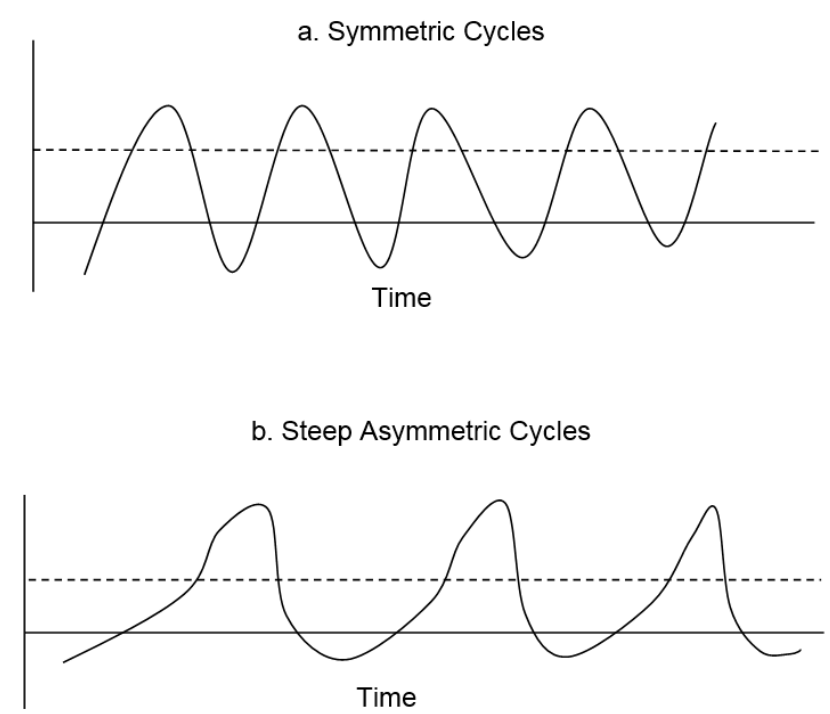

Graph 1. Symmetric and asymmetric Business cycle Source: Elaboration based on Sichel (1993)

Other extensions are presented with autoregressive models and with Markov's regime change (AR-CRM) and auto regressive vector models with Markov's change of regime (VARCRM) proposed by Hamilton (1989) and Engel \& Hamilton (1990).

From the empirical evidence in Bolivia, previos studies suggest two kinds of business cycle duraton: short and long-term respectively. By the first case, some papers show evidence that the bolivian business cycle has a duration between 7 and 28 quarters (about 2 to 7 years, respectively), where the recessive stages are presented from two to three quarters and the stage of recovery in five quarters (more than one year) (Valdivia and Yujra, 2009).

For the long-term approach, Mercado, Leitón and Chacón (2005) found two long-term cycles in Bolivia with an average duration of 30 years, which coincides with that of Humérez y Dorado (2006, p. 9): the first one of 31 years (1951-1983), and the second one of 30 years (1983-2003), but in 1968, the highest growth rate was found $(7.18 \%)$.

\section{Methodological approach}

\subsection{Econometric data and specifications}

Based on information from Feenstra, Inklaar, and Timmer (2015), the World Penn Table, the Social and Economic Policy Analysis Unit (UDAPE, 2016) and the National Statistics Institute of Bolivia ([INE], 2016), a consistent series was built for the real product of Bolivia [Y_t] (at constant 2005 prices), as well as the occupied population as a working factor [L_t] and the total population [N_t] from 1950 to 2015.

\subsection{Time series filters}

In the same way, three time-series filters were used (Christiano and Fitzgerald, 2003; Baxter and King, 1999; Ravn and Uhlig, 2002) with the purpose of evaluating the consistency in economic fluctuations and avoiding spurious cycles (Kydland and Prescott, 1990). Consequently, it proceeded with a breakdown of each original series $\left(y_{t} T h e\right)$-real product, 
real product per worker and real product per capita- in two components: cyclic fluctuations $\left(\varsigma_{t}\right)$ and long term trend $\left(\tau_{t}\right)$ :

$$
y_{t}=\varsigma_{t}+\tau_{t}
$$

The first considered filter (Christiano and Fitzgerald, 2003) is a method of a linear optimization, which consists of selecting filter weights, so that $\tau_{t}$ approaches in the best way to the series of interest $y_{t}$, and the quadratic expected error is minimized:

$$
E\left[\left(y_{t}-\tau_{t}\right)^{2} \mid x\right], x \equiv\left[x_{1}, x_{2}, \ldots, x_{T}\right]
$$

Where $\tau_{t}$ is the linear trend of $y_{t}$ over each element of the database $x_{t}$, where the problem is the projection time $t$; therefore, the solution focuses on the filter weightings. The core of this filter is that the business cycle $\left(s_{t}\right)$ contains a high-frequency component. In practice, this filter eliminates the initial and final observations to avoid the problem of the starting point and the endpoint (band-pass).Three forward periods and three previous periods were used for the band-pass filters; after 2015, an expected scenario was projected for the real GDP growth up to 2020 as a simple average between external forecasts of the IMF (2015) and the Government of Bolivia.

The second filter (Baxter and King, 1999) is also a band-pass that allows the capture of cyclic fluctuations $\left(s_{t}\right)$ of a time series $\left(y_{t}\right)$, in a stationary sense, as well as its trend component $\left(\tau_{t}\right)$. Cyclical components are constructed through moving averages at a specific frequency band:

$$
\begin{aligned}
& \varsigma_{t}=a(L) y_{t} \\
& a(L)_{-r}^{s}=a_{-r} L^{-r}+\cdots+a_{0}+a_{1} L+a_{s} L^{s} \\
& \tau_{t}=[1-a(L)] y_{t}
\end{aligned}
$$

Where $a(L)$ is a polynomial operator in lag $L$, which specifies the lag's size $[-r, s]$ of the model, which are usually symmetrical and two bands; consequently, the size of future and past values determine the value of the trend $\left(\tau_{t}\right)$.

To finalize the last filter (Ravn and Uhlig, 2002), a modification to the filter of Hodrick and Prescott (1980) [HP] was proposed. This generates false and erratic fluctuations, by showing that the parameter of the filter should be adjusted with the fourth power of reason of observation frequency (based on quarterly periods), and an equivalent penalty parameter $(\lambda)$ to 6.25 for annual data. The results will be similar to that of Baxter and King (1999), with the peculiarity that no observations will be lost. Below, the original version is presented [HP]:

$$
\min _{\left\{\tau_{t}\right\}} \sum_{t=1}^{T}\left(y_{t}-\tau_{t}\right)^{2}+\lambda \sum_{t=2}^{T-1}\left[\left(\tau_{t+1}-\tau_{t}\right)-\left(\tau_{t}-\tau_{t-1}\right)\right]^{2}
$$

Consequently, through the three filters, production gaps and the expressions (7), (8) and (9) are obtained:

$$
\begin{aligned}
& \varsigma_{y_{t}} \text { gap } y_{t}=l y_{t}-l y_{t}^{*} \\
& \varsigma_{y / l_{t}}=g a p y / L_{t}=l y / L_{t}-l y / L_{t}^{*} \\
& \varsigma_{y / N_{t}}=g a p y / N_{t}=l y / N_{t}-l y / N_{t}^{*}
\end{aligned}
$$

Where $y_{t}$ represents the real effective GDP; $y / L_{t}$ is the product per effective worker and $y / N_{t}$ is the product effective per capita, while the variables are measured in logarithmic 
scale $(l)$. The symbols $y_{t}^{*}, y / L_{t}^{*}$ and $y / N_{t}^{*}$ correspond to the trends or potential production levels, product per worker and income per capita in their respective form.

According to the procedure recommended by Sichel (1993), the interest in the gaps (7), (8) and (9) (or cyclical stationary components) is on determining their asymmetry and steep level. If a series of time exhibits in-depth asymmetry, a negative asymmetry is presented around its average or central tendency. Although, there are a few below-average observations, on the average, they exceed the positive gaps. Consequently, the depth asymmetry coefficient $[A P(S)]$ is calculated:

$$
A P(\varsigma)=\left[(1 / T) \sum_{t} \quad\left(\varsigma_{t}-\underline{s}\right)^{3}\right] / \sigma(\varsigma)^{3}
$$

Where $\underline{\underline{s}}$ is the average value of $\varsigma_{t}, \sigma$ is the standard deviation of $\varsigma_{t}$ and $T$ is the sample size. On the other hand, if the time series exhibit asymmetry by the steep level, then the first difference of the cyclic component should reflect a negative asymmetry: pronounced and longer, but with less frequent valleys. Consequently, it is calculated through the steep asymmetry coefficient:

$$
A E(\Delta \varsigma)=\left[(1 / T) \sum_{t} \quad\left(\Delta \zeta_{t}-\underline{\Delta}\right)^{3}\right] / \sigma(\Delta \zeta)^{3}
$$

Where $\Delta \zeta$ is the average value of $\Delta \zeta_{t}, \sigma$ is the standard deviation of $\Delta \zeta_{t}$ and $T$ is the sample size by checking descriptive statistics (Appendix 1).

\subsection{The Harding and Pagan Algorithm}

The Harding and Pagan (2002) algorithm, based on Bry and Boschan (1971) (BB), identifies turning points when considering maximum points (local maximum positive gap) and minimum points (local minimum negative gap) in the economic series, whereas, the one business cycle can be made from peak to peak (from maximum to maximum), or from valley to valley (from minimum to minimum). Consequently, a BB business cycle can be adapted (originally from monthly data) to a generalization of quarterly or yearly data:

Identification of the business cycle peak (relative local maximum):

$$
\begin{gathered}
\Delta_{2} y_{t}>0 \cap \Delta y_{t}>0 \cap \Delta y_{t+1}<0 \cap \Delta y_{t+2}<0 \\
(+) \quad(+) \quad(-) \quad(-)
\end{gathered}
$$

Identification of the business cycle valley (relative local minimum):

$$
\begin{aligned}
& \Delta_{2} y_{t}<0 \cap \Delta y_{t}<0 \cap \Delta y_{t+1}>0 \cap \Delta y_{t+2}>0 \\
& (-) \quad(-)
\end{aligned}
$$

Where $\Delta_{2} y_{t}=y_{t}-y_{t-2} \& \Delta y_{t}=y_{t}-y_{t-1}$

The properties of the algorithm refer to the series description of the economic growth: which does not only apply to the classical version of the theory of business cycle (observed 
rates of growth and turning points), but it also applies to growth gaps between the effective product and the potential product (Cotis \& Coppel, 2005).

\subsection{Autoregressive model with Markov's regime-switching model (AR-CRMM)}

Markov's chain is used when a particular variable moves from one regime to another or returns to the same regime, but the variable that produces the change may or might not remain unobservable. The used specification is as follows:

$$
\begin{aligned}
& \text { Markov's chain process for economic growth } \\
& \Delta y_{t}-\mu_{s_{t}}=\varphi_{1}\left(\Delta y_{t-1}-\mu_{s_{t-1}}\right)+\varphi_{2}\left(\Delta y_{t-2}-\mu_{s_{t-2}}\right)+\varphi_{p}\left(\Delta y_{t-p}-\mu_{s_{t-p}}\right)+\varepsilon_{t}
\end{aligned}
$$

In (14), $\Delta y_{t}$, corresponds to a proxy variable of economic growth, expressed in a stationary sense [I(1)] that it is verified by Augmented Dickey Fuller test (ADF, Appendix 2); $s_{t}$ implies two growth states: an increment state $\left[s_{t}=1\right]$ and a stagnation or economic contraction $\left[s_{t}=2\right]$ of respective form $\{\mathrm{t}=1.2\} ; \mu_{t}$ corresponds to the conditional mean and $\varepsilon_{t} \sim N\left(0, \sigma^{2}\right)$ (Engel and Hamilon, 1990). Consequently, the state movements of economic growth are structured in regimes managed by the Markov's processes. This Markov's process can be expressed by:

$$
P\left[a<\Delta y_{t}<b \mid \Delta y_{1}, \Delta y_{2}, \ldots, \Delta y_{t-1}\right]=P\left[a<\Delta y_{t}<b \mid \Delta y_{t-1}\right]
$$

If the economic growth variable follows a Markov's process, there is need to calculate the probability of changing the regime for the next period or to remain in the same regime as the current period, which is known as the transition matrix:

$$
P_{i j}=\left[P_{11} P_{12} P_{21} P_{22}\right]
$$

In (16), $P_{i j}$ indicates the probability of regimen change from $i$ to $j$.

Markov's chains can become complex, however, their simple version is known as the Hamilton filter. If it was assumed that there are two states $\left\{s_{t}\right\}$ for $\Delta y_{t}\{t=1,2\}$, then, the unobservable state of the analyzed dependent variable is denoted by $Z_{t}$, which involves a Markov's process with the following probabilities:

$$
\begin{gathered}
\text { Prob. }\left[Z_{t}=1 \mid Z_{t-1}=1\right]=p_{11} \\
\text { Prob. }\left[Z_{t}=2 \mid Z_{t-1}=1\right]=1-p_{11} \\
\text { Prob. }\left[Z_{t}=2 \mid Z_{t-1}=2\right]=p_{22} \\
\text { Prob. }\left[Z_{t}=1 \mid Z_{t-1}=2\right]=1-p_{22}
\end{gathered}
$$

In (17), $p_{11}$ and $p_{22}$ denote, in their respective way, the probability of remaining in the same regime under the consideration that the previous period $\Delta y_{t}$ was in the same regime. On the other hand, $1-p_{11}$ and $1-p_{22}$ indicate the probability of regime change from one state to another, given the previous behavior. The fundamental assumption is that: 


$$
\sum_{i=1}^{2} P_{i j}=1 \forall i
$$

In the same way, a current probability vector for $i$ is obtained:

$$
\pi_{t}=\left[\pi_{1}, \pi_{2}\right]
$$

When you know (18) and (19), you can project a probability that the variable $\left(\Delta y_{t}\right)$ remains in a regimen given the following period:

$$
\pi_{t+1}=\pi_{t} * P
$$

The probability for " $s$ "steps ahead will be set by:

$$
\pi_{t+1}=\pi_{t} * P^{s}
$$

In accordance with the above, through univariate autoregressive models with a change in the Markov's regime (AR-CRM), AR (p) are denoted, indicating that they are autoregressive models with $p$ lags $(1,2,3, \ldots . . \mathrm{p})$. Also, a change of regime is included in the mean of the stationary series and homoscedasticity [CRMM (M), second $M$ ] (with $M=1$ and 2, for estimates made). However, there are cases in which the presence of variance differs in the different regimes, denoted by $\mathrm{H}, \mathrm{CRMH}(\mathrm{M})$ (with $\mathrm{M}=1$ and 2): therefore, the vector of population parameters is focused on:

$$
\theta=\left[\varphi_{p}, \mu_{1}, \mu_{2}, p_{11}, p_{22}, \sigma^{2}\right]
$$

In order to maximize the probability density function:

$$
p\left(\Delta y_{1}, \Delta y_{2}, \ldots \ldots, \Delta y_{t} ; \theta\right)
$$

\section{Conducting research and results}

The preliminary analysis of the business cycle asymmetries in Bolivia, through the time $3^{\circ}$ (asymmetry coefficient) (Table 1), indicates a positive bias for gaps in the real product, product per worker and product per capita; therefore, the hypothesis of negative asymmetry indepth level is rejected.

In contrast, the results suggest the presence of asymmetric business cycle by the steep level, in the sense that the first difference in all alternative measurements of the businesscycle reflects negative asymmetry coefficients. This is interpreted by the presence of pronounced valleys, less frequent and long periods of recovery.

On the other hand, when evaluating the phases of the business cycle, five complete business cycles from peak to peak were identified, according to Table 2. This is for the case of Bolivia, from 1950 to 2015, with an average duration of 10 years and amplitude from seven to fifteen years. For the measurement of the business cycle, it is indistinct to consider the gaps in the actual product, the actual product per worker or the product per capita (the same conclusion is reached).The results of the filter of Ravn y Uhlig (2002) are shown for the estimations, which are identical to the Baxter-King and Christiano-Fitzgerald filters. Within the cyclic fluctuations, the bi-varied correlation is close to the unit. 
For the Bolivian case, according to the real product and per capita income gaps, the most severe crisis was recorded in 1953, whose period was after the process of the National Revolution in Bolivia (1952). This is related to the Nationalization of mines, agrarian reform, state participation in the economy, among other reforms.

Table 1. Asymmetries of Business cycle in Bolivia Adjusted sample: 1953-2015

\begin{tabular}{|c|c|c|c|}
\hline & \multicolumn{3}{|c|}{ Depth Asymmetry } \\
\hline Busines cycle according to: & Filter & $\mathrm{AP}(\varsigma)$ & Prob. \\
\hline \multirow[t]{3}{*}{ Real product } & $B-K$ & 0.32 & 0.45 \\
\hline & $C h-F$ & 0.12 & 0.50 \\
\hline & $R-U$ & 0.49 & 0.67 \\
\hline \multirow[t]{3}{*}{ Real product per worker } & $B-K$ & 0.65 & 0.86 \\
\hline & $C h-F$ & 0.51 & 0.86 \\
\hline & $R-U$ & 0.69 & 0.91 \\
\hline \multirow[t]{4}{*}{ Real product per capita } & $B-K$ & 0.36 & 0.43 \\
\hline & $C h-F$ & 0.50 & 0.49 \\
\hline & $R-U$ & 0.15 & 0.65 \\
\hline & \multicolumn{3}{|c|}{ Steep Asymmetry } \\
\hline Business cycle according to: & Filter & $\mathrm{AE}(\Delta \varsigma)$ & Prob. \\
\hline \multirow[t]{3}{*}{ Real product } & $B-K$ & -1.42 & 0.69 \\
\hline & $C h-F$ & -1.12 & 0.69 \\
\hline & $R-U$ & -1.58 & 0.70 \\
\hline \multirow[t]{3}{*}{ Real product per worker } & $B-K$ & -2.30 & 0.89 \\
\hline & $C h-F$ & -2.06 & 0.89 \\
\hline & $R-U$ & -2.41 & 0.88 \\
\hline \multirow[t]{3}{*}{ Real product per capita } & $B-K$ & -1.42 & 0.69 \\
\hline & $C h-F$ & -1.57 & 0.69 \\
\hline & $R-U$ & -1.12 & 0.72 \\
\hline
\end{tabular}

Source: own compilation.

The used variables were analyzed in logarithmic scale. B-K is the Baxter \& King (1999) band pass filter. Ch-F is the Christiano-Fitzgerald band pass filter (symmetrical version). R-U is the Ravn-Uhlig filter. The probability corresponds to the significance level under the null hypothesis: $(\underline{\zeta})=(\underline{\Delta})=0$ can be rejected.

Furthermore, when evaluating the length of the business cycle from troughs-to-troughs (from minimum to local minimum), Bolivia reflected an amplitude from 7 to 25 years, with an average duration of 17 years in four complete cycles. The results reflected the similarity when considering the three alternative measurements of the business cycle in terms of production gaps (real, per worker and per capita). 
Table 2. Identification of complete Business cycle with Harding and Pagan (2002) beginning and ending from peak to peak, booms

\begin{tabular}{|c|c|c|c|c|}
\hline \multirow[b]{3}{*}{$\begin{array}{l}\text { Number } \\
\text { complete } \\
\text { cycles }\end{array}$} & \multicolumn{3}{|c|}{$\begin{array}{l}\text { Business cycle in Bolivia, } 1950 \text { - } 2015 \\
\text { (Starting and ending year) }\end{array}$} & \multirow[b]{3}{*}{ Cycle interpretation } \\
\hline & \multicolumn{3}{|c|}{ Production gaps according to: } & \\
\hline & $\begin{array}{l}\text { a) Real } \\
\text { product }\end{array}$ & $\begin{array}{l}\text { b) Real } \\
\text { product per } \\
\text { worker }\end{array}$ & $\begin{array}{l}\text { c) Real } \\
\text { product per } \\
\text { capita }\end{array}$ & \\
\hline \multicolumn{5}{|c|}{...Started... } \\
\hline I & $\begin{array}{c}1952 \\
(15.00)\end{array}$ & $\begin{array}{c}1957 \\
(10.00)\end{array}$ & $\begin{array}{c}1952 \\
(15.00)\end{array}$ & Developmental policies \\
\hline II & $\begin{array}{c}1967 \\
(14.00) \\
1981\end{array}$ & $\begin{array}{c}1967 \\
(15.00) \\
1982\end{array}$ & $\begin{array}{c}1967 \\
(14.00) \\
1981\end{array}$ & Oil Boom \\
\hline III & $\begin{array}{c}(10.00) \\
1991\end{array}$ & $\begin{array}{c}(9.00) \\
1991\end{array}$ & $\begin{array}{c}(10.00) \\
1991\end{array}$ & 80 's turbulence and adjustment \\
\hline IV & $\begin{array}{c}(7.00) \\
1998\end{array}$ & $\begin{array}{c}(7.00) \\
1998\end{array}$ & $\begin{array}{c}(7.00) \\
1998\end{array}$ & Economic liberalization \\
\hline V & $\begin{array}{c}(10.00) \\
2008\end{array}$ & $\begin{array}{l}(10.00) \\
2008\end{array}$ & $\begin{array}{c}(10.00) \\
2008\end{array}$ & External price shocks \\
\hline VI & & it continues. & & \\
\hline $\begin{array}{l}\text { Range } \\
\text { Average }\end{array}$ & $\begin{array}{c}\text { Busine } \\
(7-15) \\
(11)\end{array}$ & $\begin{array}{c}\text { cycles duratio } \\
(7-15) \\
(10)\end{array}$ & $\begin{array}{c}\text { n Bolivia, ex } \\
(7-15) \\
(11)\end{array}$ & ed in years \\
\hline
\end{tabular}

Source: own data

Table 3. Identification of the Business cycle with Harding and Pagan (2002) beginning and ending from troughs to troughs, busts

\begin{tabular}{|c|c|c|c|c|c|c|}
\hline \multicolumn{7}{|c|}{$\begin{array}{l}\text { Depth of crises and negative gaps, } 1950-2015 \\
\text { Negative production gaps according to: }\end{array}$} \\
\hline & $\begin{array}{c}\text { Number of } \\
\text { negative and } \\
\text { enlarged gaps }\end{array}$ & $\begin{array}{c}\text { The effective } \\
\text { real GDP } \\
\text { growth }\end{array}$ & $\begin{array}{c}\text { Real GDP } \\
\text { potential } \\
\text { growth }\end{array}$ & $\begin{array}{l}\text { a) Real } \\
\text { product }\end{array}$ & $\begin{array}{l}\text { b) Real } \\
\text { product per } \\
\text { worker }\end{array}$ & $\begin{array}{l}\text { c) Real } \\
\text { product } \\
\text { per } \\
\text { capita }\end{array}$ \\
\hline 60's & 1961 & 1.8 & 4.0 & -2.1 & -2.3 & -2.1 \\
\hline 80 's & 1986 & -2.5 & -0.1 & -2.4 & $\begin{array}{c}-2.8 \\
(25.0)\end{array}$ & -2.4 \\
\hline 90 's & 1993 & 4.3 & 4.9 & -0.6 & $\begin{array}{l}-0.7 \\
(7.0)\end{array}$ & -0.6 \\
\hline 2000's & 2012 & 5.1 & 5.9 & $\begin{array}{r}-0.8 \\
\text { The } \\
\text { (decelerat }\end{array}$ & $\begin{array}{l}-1.0 \\
(19.0) \\
\text { tion between } \\
\text { in Bolivia, ex } \\
\text { years }\end{array}$ & $\begin{array}{l}\quad-1.3 \\
\text { ses } \\
\text { essed in }\end{array}$ \\
\hline & & $\begin{array}{l}\text { Range } \\
\text { verage }\end{array}$ & & & $\begin{array}{c}(7-25) \\
(17)\end{array}$ & \\
\hline
\end{tabular}

Source: own estimates.

The consistency of the results in the expected duration of a high economic growth regime indicates a period of 8 to 9 years in a consistent manner (actual product and actual 
product per worker) [table 4]. In addition, the Bolivian economy has a high growth regime (regime 1) to the extent that its actual growth is equal to or greater than $4.70 \%$; which is more than $2.2 \%$ in real growth per capita and above $2.6 \%$ in growth per worker. In contrast, the evidence indicates a low economic growth (regime 2), whether the growth in the actual product or the product per worker is equal to $0 \%$ or negative in terms of the per capita product.

Table 4. Non-linear regimens with univariate Markov's chains

\begin{tabular}{|c|c|c|c|}
\hline $\begin{array}{l}\text { Adjusted sample: } 1951-2015 \\
\text { Methodology: Markov chains }\end{array}$ & & & \\
\hline & $\Delta$ Real Product & $\begin{array}{l}\Delta \text { Real product per } \\
\text { capita }\end{array}$ & $\begin{array}{l}\Delta \text { Real product } \\
\text { per worker }\end{array}$ \\
\hline & $\mathrm{AR}(0)-\mathrm{CRMH}(2)$ & AR(0)-CRMM (2) & $\mathrm{AR}(0)-\mathrm{CRMH}(2)$ \\
\hline$\mu 1$ (regimen 1, growth) & $4.70 * * *$ & $2.26 * * *$ & $2.65 * * *$ \\
\hline & -0.36 & -0.38 & -0.36 \\
\hline$\mu 2$ (regimen 2, stagnation) & 1.10 & $-3.32 * * *$ & -0.12 \\
\hline & -0.92 & -0.90 & -1.08 \\
\hline $\log (\sigma 1)$ & $0.34 \dagger$ & & $0.42 * *$ \\
\hline & -0.18 & & -0.21 \\
\hline $\log (\sigma 2)$ & $1.23^{* * * *}$ & & $1.42 * * *$ \\
\hline & -0.16 & & -0.14 \\
\hline p11 & 0.89 & 0.75 & 0.88 \\
\hline p22 & 0.85 & 0.95 & 0.88 \\
\hline $\begin{array}{l}\text { Years of expected duration, } \\
\text { regimen } 1\end{array}$ & 9 & 21 & 8 \\
\hline $\begin{array}{l}\text { Years of expected duration, } \\
\text { regimen } 2\end{array}$ & 7 & 4 & 8 \\
\hline *** Statistical sig & el at $1 \% *^{*}$ & $0 ; \dagger$ at $10 \%$ resp & \\
\hline $\mathrm{J}-\mathrm{B}$ & 0.31 & 0.06 & 0.44 \\
\hline
\end{tabular}

Source: own estimates.

According to the non-linear estimations, through the filtered probability (Graph 2), it is possible to identify the periods of sustained growth (shaded areas) and on the reverse, the periods of stagnation or economic contraction (especially in the 50's and the 80's for Bolivia) with levels of probability for growth rate sustained near zero.

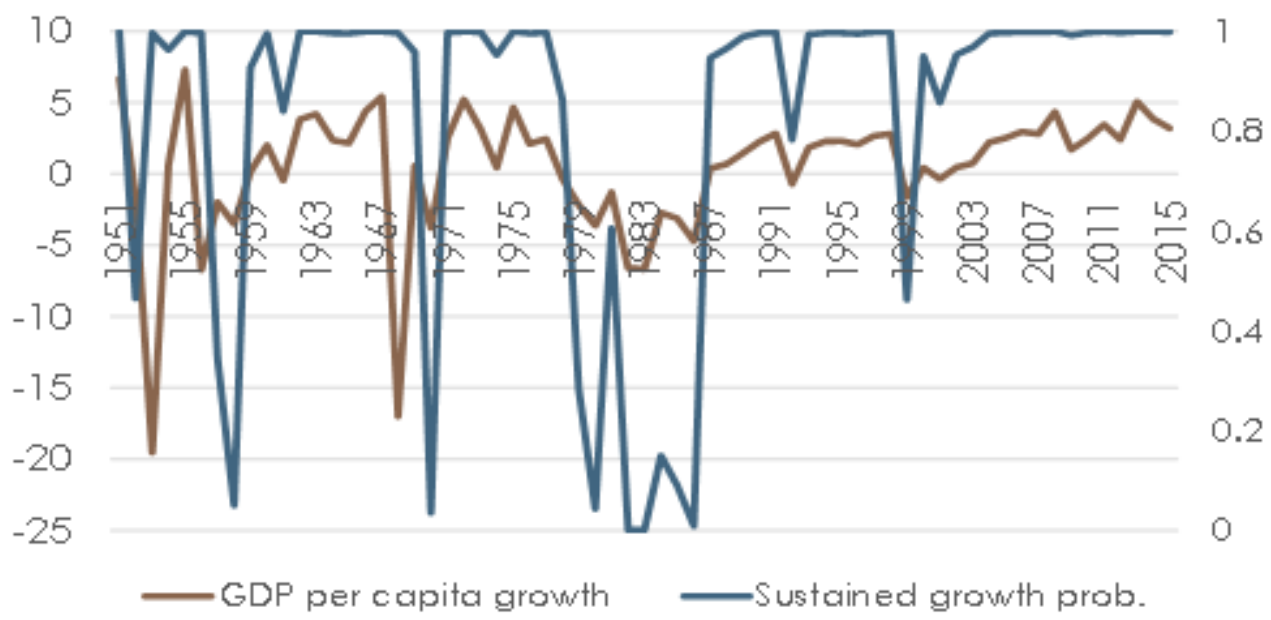

Graph 2. Filtered probability

Source: own estimates. 


\section{Results discussion}

Although the measurement and quantification of the business cycle lead to empirical strategies with predominance over the theoretical debate, it deals with the discussion of the dichotomy between the presence of regular cycles over time versus irregular cycles, asymmetric with non-linear regimes in periods of growth and economic contraction. In addition, operationalizing variables can significantly change the conclusions of the inferences.

In advanced economies, there is evidence of an increasing negative business cycle asimetries and nonlinearities dynamic, as also for some oil-dependent countries (Hensen et al., 2020; Fritz, Gries \& Feng, 2019; Taheri et al., 2020), but not neccesarily with strong evidence for developing countries.

The business cycle is a construct whose observation comes from a definition. In this sense, based on the contribution of Lucas (1975), who observed that the business cycle is linked to the trajectory of the effective product around a trendline (potential product), it is also involved in the quantification in terms of gaps (real product, Product per worker and product per capita).

The results of the estimates, based on a small and open economy (case of Bolivia) and through the algorithm of Harding and Pagan (2002), reflect that the duration periods of the peak to peak are different from the duration periods of troughs-to-troughs cycle. Therefore, the regimens are asymmetric with evidence of negative biases for the breading level: relative troughs or minimums are not frequent but have long recovery periods (Sichel, 1993).

From a non-linear perspective, it is evident that the same conclusion was reached for the expansion and contraction regimes in the product and product variation rate per worker, in the sense that the production and employment are directly linked with medium-term cycle implications. This is indistinct from the measurement of per capita income (long-term cycles), which coincides with some previous studies in Bolivia (Mercado, Leitón \& Chacón, 2005; Humérez \& Dorado, 2006). However, the expansion periods are five times longer than the contraction or stagnation regimes.

\section{Implications for public policies and research agenda}

The importance of addressing a non-linear growth modeling allows the determination of the natural growth rate of the economy in two regimes: sustained growth and stagnation or contraction.

As also, the nonlinearities in business cycle hase some relevant aspect for public policies, specially with the effects of fiscal and monetary policy, for assesment of expansionary and contractionary design according to the state of the cycle, as also as duration of respective regimen. Therefore, by measures of nonlinearities is an effective approach to describe business dynamic behavior (Lopes \& Zsurkis, 2019), specially by determining the natural rate of growth.

In the case of the Bolivian economy, a natural rate of growth in the real GDP of $4.7 \%$ is evident, $2.3 \%$ in the product per worker and $2.7 \%$ in per capita income. Under these parameters, the Bolivian economy would double its income level in 26 years. Consequently, it is possible to compare the estimates in growth rates with previous studies for Bolivia at the natural level (Table 5): 
Table 5. The natural rate of the economy real growth

\begin{tabular}{lll}
\hline Estimations & Period & The natural rate of real growth \\
Research developed*** & $1950-2015$ & $4.70 \%$ \\
\hline Valdivia and Yujra (2009) & $1990-2008$ & $4.49-5.17 \%^{\mathrm{a}}$ \\
\hline Jemio (2008) & $1971-2006$ & $3.79 \%$ \\
\hline Humérez and Dorado (2006) & $1960-2004$ & $4.40 \%$ \\
\hline Mercado, Leitón and Chacon (2005) & $1988-2003$ & $4.04 \% \mathrm{o}^{\mathrm{b}}$ \\
\hline \multirow{2}{***}{ Results of own estimates } & \\
${ }^{a}$ Time series filter methodology: Nardaraya-Watson and Christiano-Fitzgerald \\
${ }^{b}$ Long-term product equation trend with quarterly annualized data
\end{tabular}

As a final reflection on the estimates limitations and the research agenda for future work, there is need to include conditional variables of turning point or regime change (expansion and contraction) from a non-linear perspective or through autoregressive vectors with Markov's innovations.

\section{Conclusions and final reflections}

This paper addressed the characterization of the business cycle in Bolivia for the period of 1950-2015. The theoretical discussion of regular cycles was done in contrast with asymmetric phases between the expansions and recessions of the economy. For this purpose, filters were used in different measurements of the business cycle. The Harding and Pagan (2002) algorithm was used for the cyclical fluctuations of the actual product, the product per worker and the per capita income. Alternatively, a non-linear-specification, based on Markov's chains, was considered to identify the expansion regimes and the stagnation-economic contraction.

The results obtained suggest that the business cycle in Bolivia presents a medium-term characteristic, with an average duration between nine and eleven years for peak-to-peak measurements (maxima relatives). However, the duration phases are asymmetric for troughsto-troughs measurements (relative lows) with periods being up to 25 years.

In general, there is no conclusive evidence of asymmetry in the business cycle of Bolivia by the depth level of economic recessions. However, the results suggest the presence of asymmetries at the steep level (negative bias) with troughs or not frequent relative minimums, but with long periods of recovery in attribution to the so-called rule of the 70 . For the period 1950-2015, under a sustained expansion or growth regime, implicit rates hold: $4.7 \%$ annually in the actual product annual growth and about $2.0 \%$ in the annual population growth.

From a non-linear side, expansion regimes demonstrate consistent behavior towards medium-term cycles for the actual product and product growth per worker. Nevertheless, for growth rates of per capita income, the cycle duration is asymmetric, demonstrating long-term cycles in the expansion regime (duration greater than twenty years) and duration of four years in the contraction and economic stagnation regime. Finally, a natural yearly rate of $4.7 \%$, interpreted as the natural rate in a sustained growth regime was found. 


\section{References}

Alfonso, V., Arango, L. E., Arias, F., Cangrejo, G., \& Pulido, J. D. (2013). Business cycles in Colombia, 1975-2011. Lecturas de Economía, 78, 115-149. https://www.redalyc.org/pdf/1552/155226987004.pdf

Baxter, M., \& King, R. G. (1999). Measuring business cycles: approximate band-pass filters for economic time series. Review of economics and statistics, 81(4), 575-593. https://doi.org/10.1162/003465399558454

Bry, G., \& Boschan, C. (1971). Front matter to "Cyclical Analysis of Time Series: Selected Procedures and Computer Programs". In G. Bry, and C. Boschan, Cyclical Analysis of Time Series: Selected Procedures and Computer Programs. NBER.

Burns, A., \& Mitchell, W. (1946). Measuring Business Cycles. New York: National Bureau of Economic Research. https://econpapers.repec.org/bookchap/nbrnberbk/burn46-1.htm

Christiano, L. J., \& Fitzgerald, T. J. (2003). The band pass filter*, International economic review, 44(2), 435-465. https://doi.org/10.1111/1468-2354.t01-1-00076

Cotis, J., \& Coppel, J. (2005). Business cycle dynamics in OECD countries: evidence, causes and policy implications. Changing Nature of the Business Cycle. Reserve Bank of Australia $2005 \quad$ Conference Proceedings, Sidney.http://www.oecd.org/economy/growth/35125435.pdf

Engel, C., \& Hamilton, J. D. (1990). Long swings in the dollar: Are they in the data and do markets know it? The American Economic Review, 689-713. https://www.jstor.org/stable/2006703

Feenstra, R. C., Inklaar, R., \& Timmer, M., P. (2015). The Next Generation of the Penn World Table. American Economic Review, 105(10), 3150-3182. http://dx.doi.org/10.1257/aer.20130954

Fritz, M., Gries, T., \& Feng, Y. (2019). Growth Trends and Systematic Patterns of Booms and Busts-Testing 200 Years of Business Cycle Dynamics. Oxford Bulletin of Economics and Statistics, 81(1), 62-78. https://doi.org/10.1111/obes.12267

Jensen, H., Petrella, I., Ravn, S. H., \& Santoro, E. (2020). Leverage and Deepening BusinessCycle Skewness. American Economic Journal: Macroeconomics, 12(1), 245-81. https://doi.org/10.1257/mac.20170319

Hamilton, J. D. (1989). A new approach to the economic analysis of nonstationary time series and the business cycle. Econometrica: Journal of the Econometric Society, 57(2), 357384. https://doi.org/0012-9682(198903)57:2<357:ANATTE>2.0.CO;2-2

Harding, D., \& Pagan, A. (2002). Dissecting the cycle: a methodological investigation. Journal of Monetary Economics, 49(2), 365-381. https://doi.org/10.1016/S0304-3932(01)001088

Hodrick, R., \& Prescott, J. (1980). Postwar U.S. Business Cycles: An Empirical Investigation.Carnegie Mellon University discussion paper, No. 451.https://doi.org/10.2307/2953682

Humérez, J., \& Dorado, H. (2006). Una aproximación de los determinantes del crecimiento económico en Bolivia 1960-2004. [Anapproximation of thedeterminants of economicgrowth in Bolivia 1960-2004]Análisis Económico, UDAPE, 21, 1-39. http://www.udape.gob.bo/portales_html/analisiseconomico/analisis/vol21/Hum\%C3\%A 9rez-Dorado-21.pdf

International Monetary Fund ([IMF] October, 2015). World International Monetary Fund. World Economic Outlook (WEO): http://www.imf.org/external/datamapper/index.php 
Jemio, L. (2008). La inversión y el crecimiento en la economía boliviana. [Investment and growth in theBolivianeconomy].Instituto de investigaciones Socio Económicas (IIEC). Documento de trabajo $\mathrm{N}^{\mathrm{0}} 01 / 08$.

Jevons, W. (1874). The principles of Science. London: Macmillan.

Jevons, W. (1884). Investigations in Currency and Finance.London: Macmillan.

Juglar, C. (1862). Des crises commerciales et de leur retour périodique en France.Lyon: ENS Edition. https://doi.org/10.4000/books.enseditions.1382

Koopmans, T. C. (1947). Measurement without theory. The Review of Economics and Statistics, 29(3), 161-172.https://doi.org/10.2307/1928627

Kydland, F., and Prescott, E. (1990). Business Cycles: Real Facts and Monetary Myth. Federal Reserve Bank of Minneapolis Quarterly Review, 14(2), 3-18. https://ideas.repec.org/a/fip/fedmqr/y1990isprp3-18nv.14no.2.html

Lopes, A. S., \& Zsurkis, G. F. (2019). Are linear models really unuseful to describe business cycle data? Applied Economics, 51(22), 2355-2376. https://doi.org/10.1080/00036846.2018.1495825

Lucas, J. R. (1975). An equilibrium model of the business cycle. The Journal of Political Economy, 83(6), 1113-1144. https://doi.org/10.1086/260386

Mercado, A., Leitón, J., \& Chacón, M. (2005). El crecimiento económico en Bolívia (1952 2003). [Economicgrowth in Bolivia (1952-2003)].Workingpaper (Instituto de Investigaciones Socio-Económicas (IISEC), no. 01/05). https://www.econstor.eu/bitstream/10419/72812/1/501599452.pdf

Mitchell, W. C. (1913). Business Cycles and their Causes. Berkeley: California, University Memoirs, Vol. III. https://fraser.stlouisfed.org/files/docs/publications/books/mitch_buscyc/mitchell_buscyc .pdf

Mitchell, W. C. (1927). Economic Organization and Business Cycles. In Business cycles: the problem and its setting (pp. 61-188), New York: NBER. (January 26, 2018). http://www.nber.org/chapters/c0681.pdf

Moore, H. (1914). Economic Cycles- Their Low and Cause. New York: Macmillan.

Morgan, M. (1990). The history of econometric ideas. London: Cambridge University Press.

National Statistics Institute of Bolivia ([INE], February 2016. Instituto Nacional de Estadísticas de Bolivia.Statistics.

Neftçi, S. N. (1984). Are economic time series asymmetric over the business cycle? The Journal of Political Economy, 92(2), 307-328. http://dx.doi.org/10.1086/261226

Pruden, H. (1978). The Kondratieff Wave. Has the United States economy entered a lown-term downtrend? Journal of Marketing, 42, 63-70.

Ravn, M. O., \& Uhlig, H. (2002). On adjusting the Hodrick-Prescott filter for the frequency of observations. Review of economics and statistics, 84(2), 371-376. https://doi.org/10.1162/003465302317411604

Sichel, D. E. (1993). Business Cycle asymmetry: a deeper look. Economic Inquiry, 31(2), 224236. https://doi.org/10.1111/j.1465-7295.1993.tb00879.x

Social and Economic Policy Analysis Unit ([UDAPE], February 2016) Unidad de Análisis de Políticas Sociales y económicas. Statistics.

Taheri, A., Nessabian, S., Moghaddasi, R., Arbabi, F., \& Damankeshideh, M. (2020). Business Cycles in Some Selected Oil Producing Countries: Iran versus Three OECD Members. Applied Economics Journal, 27(1), 52-74.

Terasvirta, T., \& Anderson, H. M. (1992). Characterizing nonlinearities in business cycles using smooth transition autoregressive models. Journal of Applied Econometrics, 7(S1), S119S136. https://doi.org/10.1002/jae.3950070509 
Valdivia, D., \& Yujra, P. (2009). Identification of business cycles in Bolivia: 1970-2008. Working Paper. (Munich Personal RePEc Archive, no. 35884). https://mpra.ub.unimuenchen.de/35884/1/MPRA_paper_35884.pdf

Yule, G. U. (1926). Why do we sometimes get nonsense correlations between time-series? Journal of the Royal Statistical Society, 89(1), 1-63. https://doi.org/10.2307/2341482

Zarnowitz, V., \& Ozyildirim, A. (2006). Time series decomposition and measurement of business cycles, trends and growth cycles. Journal of Monetary Economics, 53(7), 17171739. https://doi.org/10.1016/j.jmoneco.2005.03.015 


\section{Appendix}

Appendix 1. Descriptive Statistics

\begin{tabular}{lccc}
\hline$\Delta$ Real Product & $\Delta$ & $\begin{array}{c}\text { Real product per } \Delta \\
\text { capita }\end{array}$ & $\begin{array}{c}\text { Real product per } \\
\text { worker }\end{array}$ \\
\hline Mean & 2.64 & 0.49 & 0.77 \\
Median & 4.09 & 2.02 & 1.82 \\
Maximum & 9.45 & 7.29 & 8.77 \\
Minimum & -17.40 & -19.52 & -20.44 \\
Std. Dev. & 4.52 & 4.55 & 4.56 \\
Skewness & -2.27 & -2.26 & -1.81 \\
Kurtosis & 10.10 & 9.98 & 8.83 \\
Jarque-Bera & $192.41^{* * *}$ & $187.21^{* * *}$ & $127.55^{* * * *}$ \\
\hline
\end{tabular}

$* * *$ Significance level at $1 \%$

Appendix 2: Unit root analysis: Augmented Dickey Fuller Test

Ho: The variable is non-stationary/ it has unit root

\begin{tabular}{llll}
\hline & $\Delta$ Real Product & $\Delta \quad \begin{array}{c}\text { Real product } \\
\text { capita }\end{array}$ & $\begin{array}{c}\text { per } \\
\text { worker }\end{array}$ \\
\hline ADF & $-6.85^{* * *}$ & $-4.32^{* * *}$ & $-5.19^{* * *}$ \\
Lags & 0 & 1 & 0 \\
Specification & Intercept & No-intercept & No-intercept \\
\hline
\end{tabular}

***Significance level at $1 \%$ 